\title{
FAMILIA Y POLÍTICAS PÚBLICAS EN AMÉRICA LATINA Y MÉXICO
}

\section{Antonio Sandoval Ávilal}

\section{La seguridad social en América Latina y México}

En México y América Latina en la década de los 40 del siglo pasado, el patrón productivo de posguerra necesitaba fuerza de trabajo con cierto nivel de preparación, lo cual requería la formación de los obreros, algo que los capitales individuales no podían lograr debido a la baja o nula rentabilidad que esto representaba. La respuesta a esto fue la seguridad social como un proceso de socialización y administración del costo de la gestión social de la reproducción de la fuerza de trabajo. Entre 1940 y 1970, se conformó en la región una clase trabajadora heterogénea con formas diversas de inserción en la producción (Laurell, 1997: 179-182).

En la construcción de la seguridad social jugó un papel importante el corporativismo, entendido como un sistema de representación de intereses caracterizado por asociaciones ocupacionales que representan los intereses de sus miembros mediante negociaciones directas con el Estado. Las instituciones de protección social funcionaron como un canal de relación entre líderes populistas y la clase trabajadora urbana, conformando una función de intercambio de apoyo y legitimidad entre los gobiernos y la clase trabajadora.

La prioridad dada a las demandas de los trabajadores urbanos propició diferentes niveles de protección social, en concordancia con el grado de organización de la clase trabajadora. De esta manera, la seguridad social, que se originó en gran parte como producto del juego político de presión y negociación entre el Estado y la clase trabajadora, además de ser un fenómeno predominantemente urbano, surge como un sistema de privilegios diferenciales para los grupos más poderosos, tales como: militares, burócratas, y algunas fracciones de la clase obrera, con

\footnotetext{
${ }^{1}$ Docente e investigador, Departamento de Sociología, Centro de Ciencias Sociales, Universidad de Guadalajara.
} 
exclusión de ciertos grupos ocupacionales como campesinos y empleados domésticos. El resultado fue un sistema de asistencia social fragmentado y de cobertura incompleta que, no obstante, significó un avance en las condiciones de vida de los trabajadores.

El populismo generó la emergencia de un poderoso control estatal sobre la sociedad, que ejercía una incorporación controlada de las demandas de los trabajadores urbanos, subordinado a compromisos que rebasaron la capacidad de respuesta del Estado por la contradicción generada por la magnitud de los compromisos adquiridos y las posibilidades reales de cumplir con ellos. La imposibilidad del Estado de atentar contra los intereses de los grupos aliados, propició una atención indiscriminada de demandas; el acuerdo con los sectores productivos limitó su capacidad para imponer una política fiscal menos proteccionista, lo cual agravó la crisis fiscal del Estado.

En la década de los 70, la complejidad de la estructura política, la presión de los acreedores internacionales y la insatisfacción generada por el incumplimiento de expectativas, hicieron difícil la satisfacción de las demandas sociales emergentes, lo que produjo una crisis política que fue desgastando los pactos corporativos que habían garantizado la estabilidad durante varias décadas. En varios países de la región hubo un colapso de los esquemas populistas que llevó a la instauración de sistemas autoritarios. En algunos países como México, se intentó disciplinar a algunos grupos de obreros a través de beneficios selectivos (salud entre otros), pero ante el recrudecimiento de la crisis económica en la década de los 80 , los gobiernos tuvieron que reducir los subsidios al bienestar social (Tamez, 1998: 8-9).

A partir de esta década la situación se tornó insostenible debido a la fuerte dependencia que tenía en el financiamiento externo. El Estado de bienestar entra en crisis que se profundiza en la década de los ochenta a causa del creciente déficit fiscal (por falta de una adecuada política impositiva y de una reestructuración tributaria) y de los procesos inflacionarios consecuencia del servicio de la deuda externa que tuvo su origen en la crisis de las finanzas del sector público y de la balanza de pagos. El crecimiento económico disminuyó, lo cual constituyó un 
gran problema que creó las condiciones para que emergieran políticas de ajuste que tensionaron la relación entre lo económico, lo político y lo social en el marco de un proceso de globalización y de recomposición geopolítica del mundo (Rozas, 2001: 153-156, 177).

La globalización cambió el funcionamiento de la economía, el Estado y las organizaciones sociales (Cortázar, 1999: 99). Una de las consecuencias más importantes de la globalización se manifiesta tanto en la organización del empleo como en el mercado laboral. Las tasas promedio de desempleo aumentaron entre 1980 y 1985 , pero hacia 1994 cayeron a niveles que recordaban los de los años setenta. La política económica soslayó por entero la dimensión social (O’Donell, 1999: 78, 160-161).

Después de transitar en la década de los ochenta en medio de avances y retrocesos, en la década de los noventa el panorama experimentó un cambio con una disminución de la inflación y la reanudación del crecimiento (Torre, 1998: 114). La agenda prevaleciente en esta década trajo la promesa de que la revolución tecnológica, unida a la globalización de los mercados, produciría un desarrollo sin precedentes que beneficiaría a la gran mayoría. No obstante, a poco más de una década las expectativas en gran parte no se han cumplido. Se asumió que las reformas macroeconómicas y estructurales, la apertura comercial regional y global, los procesos de privatización y desregulación, un nuevo equilibrio entre Estado y mercado, al surgimiento de las ONGs en la esfera pública, unido a un proceso de democratización en lo político y de fortalecimiento de las capacidades administrativas a través de la nueva gestión pública, iban a poner el mundo en un camino de libertad y prosperidad sin precedentes.

Pero lo que ha sucedido es que las protecciones sociales han dejado de ser válidas como derechos sociales. El bienestar social se ha convertido en asistencialismo focalizado que no ha podido evitar la vulnerabilidad de las familias y de los individuos frente al desempleo y la pobreza (Vite, 2003: 49-51). El crecimiento del empleo no sólo ha sido escaso, sino que ha estado conformado por el empleo inestable que ha tendido a abarcar tanto al sector formal de la economía como al informal (Rozas, 2001: 199). Esto resquebraja las solidaridades basadas en las 
condiciones de trabajo y en los modos de organización del trabajo. La descolectivización y desestandarización del trabajo han permitido la generación de estrategias más individuales que colectivas para sobrevivir (Vite, 2003: 35).

La aplicación global de las medidas de liberalización ha dado origen a un deterioro significativo de las condiciones socioeconómicas de gran parte de la población mundial. Tales medidas han erosionado seriamente la capacidad de los países en vías de desarrollo para impulsar y promover sus intereses nacionales. El Banco Mundial y El Fondo Monetario Internacional han reconocido el retroceso en gran número de países en las condiciones de su desarrollo, en muchos casos hasta niveles alcanzados en 1970, y lo explican en términos de errores de juicio o de fallas políticas, de incapacidad o falta de disposición de ciertos países para realizar consecuentemente las políticas prescritas y adoptar los cambios institucionales exigidos (Petras, 2002: 24, 2728).

En América Latina la transferencia de recursos al extranjero por concepto de pago de la deuda externa, influyó en la baja de la tasa de inversión y en la significativa caída del Producto Interno Bruto (PIB). De una tasa de crecimiento media anual de $5.6 \%$ entre 1945 y 1980 , se pasó a una tasa de $1.2 \%$ en la década de los ochenta. Entre 1990 y 1995 , la tasa media anual de crecimiento fue de $2.6 \%$, poco menos de la mitad de la tasa alcanzada entre 1945 y 1980. En México, la tasa media anual de crecimiento del PIB entre 1945 y 1980 , fue de $6.7 \%$, en la década de los ochenta fue de $1.2 \%$ y entre 1990 y 1995 de $0.9 \%$ (Salama, 1999: 259).

En México, la apertura comercial unilateral previa al Tratado de Libre Comercio (TLCAN), efectuada entre 1985 y 1989, sentó las bases para que con este tratado se agudizaran los desequilibrios económicos. Las consecuencias fueron la desindustrialización, la desaparición de miles de pequeñas y medianas empresas, el desempleo y un creciente déficit de la balanza comercial. Las economías con mayor déficit son las de Argentina, México, Perú y los países centroamericanos (Salama, 1999: 260-264).

El elevado servicio de la deuda externa, la insuficiencia del ahorro interno y la inversión especulativa, llevan a una tasa de inversión 
insuficiente para crear nuevos puestos de trabajo. No se compensa la destrucción de empleos con la creación de nuevos puestos, por la insuficiente formación de capital fijo y por el débil incremento de la productividad. El desempleo, la inflación y la disminución del gasto en desarrollo social, diezman los ingresos familiares, informalizan cada vez más la economía y empobrecen a la población en general (Salama, 1999: 255-256, 261-262). En el bienio 1995-1996, la pobreza se incrementó drásticamente en la región. México, Argentina y Venezuela fueron los países que registraron mayor incremento desde finales de 1994 (Tamez, 1998: 7).

La nueva pobreza, entendida no sólo en términos económicos (falta de acceso a empleos, ingreso o bienes), sino también en términos sociales y políticos, se refiere no sólo al volumen de sectores pobres, sino también a su condición. Ahora incluye grupos sociales que habian logrado un cierto grado de integración social, ocupacional y educativa. A pesar de la acumulación de capital humano, estos grupos cayeron debajo de la línea de la pobreza, la que testimonia la heterogeneidad de la pobreza actual (Filgueira, 1999: 163, 205).

Las nuevas tecnologías fragmentan la producción, simplifican las operaciones y reducen costos. La maquila por ejemplo, no requiere de una fuerza de trabajo con características especiales, al contrario, demanda trabajadores con niveles bajos de preparación y fácilmente reemplazables (Laurell, 1997: 180). La globalización obliga a producir más y mejor con menos trabajadores y menos condiciones de seguridad en el empleo. De todos los países latinoamericanos, México experimentó la más drástica reestructuración desde el punto de vista del empleo. El gran déficit de puestos de trabajo ha empujado cuotas crecientes de población económicamente activa (PEA) a situaciones de supervivencia precaria en la economía informal. Lo anterior, aunado a la contracción del gasto público y el control sobre los salarios, ha afectado la vida cotidiana de millones de personas en todo el mundo. Pues esto ha provocado modificaciones en el microambiente familiar que han alterado la estructura y dinámica de las familias, sobre todo de las familias trabajadoras, que se han visto obligadas a implementar diversas estrategias de supervivencia, desde cambios en los hábitos alimenticios que llevan a la desnutrición, hasta el uso de la familia extendida y la incorporación al mercado informal de trabajo de todos 
los miembros de la familia en capacidad de trabajar incluidas mujeres, niños y personas mayores de ambos sexos, lo que provoca desorganización familiar que repercute negativamente en la crianza de los hijos (Rozas, 2001: 198-199, 214, 217).

El empobrecimiento del trabajador redunda negativamente en las posibilidades de expansión y mantenimiento de la seguridad social. La disminución del poder adquisitivo del salario real, que no permite remontar la línea de la pobreza, y el limitado poder de negociación del salario por parte de los trabajadores por las altas tasas de desempleo, redunda negativamente en la posibilidad de expansión y mantenimiento de la seguridad social, pues la extensión de cobertura no ha coincidido con el crecimiento del empleo (la primera es mayor que el segundo). Esto ocasionó disminución en los aportes del financiamiento de la seguridad social, lo cual, aunado a la elevación en los costos de ésta, llevó al desfinanciamiento de los sistemas de seguridad social. La crisis financiera de la seguridad social en México en gran parte se explica por esto (Tamez, 1998: 7).

En la década de los 90, la crisis económica obligó a los gobiernos de la región a impulsar diversas acciones en el terreno económico, dirigidas principalmente a combatir la pobreza. Dentro de estas acciones destacan la reactivación productiva para el crecimiento del empleo, y la reorganización de la estructura distributiva. Sin embargo, lo anterior, en ausencia de políticas eficientes para mejorar las condiciones de vida de la población y para aminorar la pauperización del mundo del trabajo que redunda en el empobrecimiento del trabajador y en el incremento de la economía informal, imposibilita la expansión y mantenimiento de la seguridad social. De esta manera, estas acciones no se han traducido en un mejoramiento de los niveles de empleo, ni en una mejor distribución de la riqueza (Tamez, 1998: 6-7).

Las medidas de ajuste se fundan en la supremacía del mercado sobre el Estado y en la centralidad del mercado como único instrumento eficaz para la asignación de recursos y la satisfacción de las necesidades básicas. Estas tesis impugnan la función social del Estado y exaltan las virtudes del Estado mínimo por medio de las privatizaciones, las desregulaciones, la abolición de subsidios y la determinación 
competitiva de tasas de interés. Con estas tesis se exacerbó la política de deprimir el costo de la fuerza de trabajo y los salarios así como el ataque al poder sindical organizado y el restablecimiento de la responsabilidad individual frente a la solidaridad colectiva. La racionalidad de las decisiones y acciones pasó a depender de la presunta objetividad de la "ciencia económica" y no de fines y objetivos dirigidos al "bien común". La política perdió su base ética. Las consecuencias de la crisis se conceptualizaron como el costo social del ajuste, "sacrificio" que es necesario para lograr el crecimiento económico que luego traerá beneficios en la esfera de lo social. Las políticas establecidas no sólo no solucionaron los problemas, sino que se agudizaron las desigualdades (Rozas, 2001: 173-175, 178-179, 181, 216).

La reestructuración de la seguridad social en América Latina y en México se ubica dentro del proceso de substitución del Estado benefactor por uno de corte neoliberal, resultado lógico de un conjunto de modificaciones legales de carácter excluyente y privatizador que ha cambiado la lógica y el sentido de la seguridad social para hacer posible la mercantilización de los servicios sociales abriendo espacios para la realización de negocios por parte de los capitalistas, y para que estos puedan disponer del ahorro de los trabajadores (privatización de los fondos de pensión de los trabajadores) para financiar sus proyectos de inversión. Se entregan a los capitalistas las áreas apropiadas que no afecten el cada vez menor nivel de preparación y salud de los trabajadores requeridos en la esfera industrial para que obtengan ganancias. Privatización por ejemplo del derecho a la salud por la vía de la subrogación de los servicios médicos; mientras que la función del Estado se limita a la provisión de un "paquete básico" de servicios de carácter asistencial (Laurell, 1997: 179-182).

En este contexto, las políticas de desarrollo social guardan relación con la política económica y responden a las estrategias que en ese campo se adoptan. Sin embargo, no se ha logrado integrar ambas en el sentido que el objetivo del modelo económico sea lograr una sociedad más justa y equitativa. Lo social ha permanecido a la zaga de la política económica y se ha supeditado a ella. En este sentido, las políticas de 
desarrollo social han respondido más que nada a las necesidades de control político de la clase gobernante en turno.

Las políticas económicas de los gobiernos no tienen como fin atender las necesidades de desarrollo social que los países requieren, sino adecuar la estructura productiva nacional a los requerimientos de las empresas transnacionales (Hernández, 1999: 10A). Las estrategias contra la pobreza generada tienen un contenido intrínsecamente asistencialista, están dirigidas más a controlar el orden que a garantizar los derechos de los ciudadanos. Se conforman con "amortiguar" las consecuencias del ajuste estructural desplazando el interés hacia los síntomas de la pobreza, relegando la temática de las causas sin incidir, por tanto, sobre el mercado laboral aumentando el empleo y el nivel de los salarios. Por lo que se refiere a la política social, la tendencia general ha sido la cristalización de un híbrido de estilos de gestión. En las viejas estructuras burocráticas se introdujeron instrumentos de gestión que en poco se acoplaban a los tradicionales valores y mecanismos de operación de los organismos públicos del área social (Pando, 2003: 1, 3-4, 6-7).

Así, la configuración actual del sector público latinoamericano para la formulación e implementación de políticas sociales, no responde a un plan racional ni a criterios técnicos discernibles. Su conformación no muestra coherencia ni en su morfología, ni en sus regímenes normativos ni en las políticas de administración de recursos. Aparece como un sector desarticulado, con un conjunto de organizaciones y programas dependientes de diversos niveles de gobierno, a veces con superposiciones y duplicaciones funcionales. La delimitación de competencias entre niveles de gobierno es confusa. Las organizaciones encargadas de las políticas sociales suelen presentar una difusa definición de misiones, objetivos, estrategias; definiciones ambiguas con respecto a beneficiarios y modalidades de trabajo. Hay una importante dispersión de esfuerzos autónomos con acciones dirigidas a la misma población meta, con criterios disímiles o contradictorios, con ausencia, a veces, de políticas sistemáticas de recursos humanos (reclutamiento, selección, integración, capacitación, remuneración, motivación). Los mecanismos de coordinación interinstitucionales e interjurisdiccionales, en la práctica muestran escasa continuidad y eficiencia. 
El resultado es que áreas completas de la actividad pública quedan sometidas a las inercias burocráticas y a las presiones corporativas, a la asignación discrecional y circunstancial de recursos, es decir, que no responde a un plan racional ni a criterios técnicos claramente definidos, con costos operativos elevados y algo de suma importancia: la carencia en muchas ocasiones, de instrumentos de supervisión y evaluación. Todo ello sin menoscabo del uso de programas como instrumentos para el clientelismo político o para la promoción de ciertos actores políticos y de la no rara malversación de fondos (Pando, 2003: 7-8).

\section{Políticas públicas orientadas a la familia}

La familia es la institución más importante a la que un individuo puede pertenecer a lo largo de su vida, y una de las mayores responsabilidades que puede tener es la de criar y educar a sus hijos. No obstante, la mayoría de las personas deben asumir sus responsabilidades familiares guiadas únicamente por su intuición y por lo que han vivido en sus propias familias de origen. Lamentablemente, para cumplir con este compromiso que requiere de la mayor responsabilidad, poco es lo que se hace en esta materia.

Sin embargo, a pesar de que a los padres se les deja solos con sus problemas de crianza de los hijos, se les exige que rindan cuentas a la sociedad. Como una de las funciones del Estado es procurar que se respeten los derechos individuales, aún en los países menos intervencionistas en materia familiar, existen leyes orientadas a la protección de los menores. Dichas leyes pueden llegar incluso a retirar la tutela de los padres cuando se demuestra (en casos por ejemplo de maltrato infantil, explotación económica, abandono, etc.) que éstos no satisfacen las expectativas que la sociedad puso en ellos como educadores para el sano y armonioso desarrollo de los niños.

De esta manera, los gobiernos asumen la responsabilidad de "calificar" el desempeño de las funciones paternas y de intervenir cuando juzgan que dichas funciones no se cumplen adecuadamente. Pero las familias, para cumplir de manera adecuada sus funciones de acuerdo con la sociedad, necesitan tener los recursos necesarios y el nivel de desarrollo suficiente que les permitan cumplir bien sus funciones y responsabilidades. 
Cuando se habla de los niños, no puede vérseles únicamente como los hijos de una familia cuyos cuidados son responsabilidad exclusiva de los padres. Puesto que constituyen el reemplazo de los adultos en la sociedad, ésta debe reconocer que tiene una responsabilidad importante en cuanto al buen o mal funcionamiento de las familias y mostrar su solidaridad con ellas apoyándolas para que puedan lograr con éxito la formación de ciudadanos útiles, capaces de vivir en armonía en la sociedad y de contribuir a su desarrollo.

El Estado debe asumir su parte de responsabilidad en la tarea de educar y formar a los futuros ciudadanos, no únicamente castigando a los progenitores cuando no cumplen adecuadamente su papel de padres, sino también completando su esfuerzo en este sentido, asistiéndolos en su tarea de educadores brindándoles todo el apoyo necesario para que puedan cumplir adecuadamente su función (Ribeiro, 2000: 16, 77-78,119, 124).

Algunas instituciones dirigidas al desarrollo integral de la familia han procurado impulsar espacios de diálogo, concertación y participación de organismos gubernamentales y no gubernamentales, desarrollando programas productivos, de salud, de rehabilitación, de apoyo a la constitución familiar, de orientación educativa, recreativa y cultural, así como de prevención y eventual solución de conflictos intrafamiliares. Se ha señalado, sin embargo, que la cobertura de muchos de estos programas es limitada y se concentran en las ciudades, carecen de mecanismos eficientes de seguimiento, control y evaluación, y requieren el fortalecimiento del esquema de integración entre los mismos y de su continuidad (CONAPO, 1995, 29).

Al considerar a la familia como el lugar privilegiado en donde se desarrolla la vida interna de los individuos, el sólo hecho de mencionarlas como el objeto de una política social que emana del gobierno, suscita inquietudes, ya que toda intervención gubernamental en ellas puede atentar contra el derecho individual a la vida privada y en este sentido se considera que el Estado no puede ni debe entrometerse en la vida privada de las personas.

Quizá por esta razón quienes diseñan las políticas de intervención en las familias aseguran que el papel del Estado es el de apoyar a éstas para el mejor logro de sus fines y para la consecución de una mejor 
calidad de vida y no el de dirigirlas, controlarlas o sustituirlas, excepto en circunstancias excepcionales. Sin embargo, dada la importancia que la familia tiene para la sociedad, el Estado sí regula diversos aspectos de la vida familiar e interviene en casos en que se demuestra que existe alguna violación a los derechos elementales de los individuos.

Todas las políticas sociales influyen de una u otra manera sobre las familias. Aunque no exista una política familiar definida como tal, los valores relacionados con la familia se encuentran en el derecho (legislación sobre la familia, el matrimonio, el divorcio, el aborto; la infancia, la adopción; sobre la asignación de pensiones alimenticias o sobre la tutela de los hijos; sobre la violencia doméstica, etc.) y en programas sociales y acciones que directa o indirectamente afectan a las familias (programas de planificación familiar, atención a discapacitados, personas de la tercera edad, etc.).

Las políticas sociales no son tan neutras como se pretende y la intervención del Estado no sólo implica programas de apoyo social, sino también una función normativa que conlleva implícitamente un trasfondo ideológico que hace que se tome en cuenta alguna o algunas concepciones de la familia, de la vida humana, de las personas y de la sociedad y que transmiten ciertos valores (económicos, morales, culturales, etc.) que se operacionalizan a través de políticas públicas, legislaciones y programas sociales. De esta manera, en cada contexto sociopolítico el Estado privilegia por sobre otras, ciertas cuestiones relacionadas con el fenómeno familiar de manera diferente. En unos casos, por ejemplo, puede adoptar posturas que apoyan la natalidad y en otras circunstancias no, según cada caso particular (Ribeiro, 2000: 17-21, 39, 118).

El objetivo principal de la familia es facilitar el crecimiento de los hijos preparándolos para que puedan, con autonomía y seguridad, enfrentarse con el mundo que los rodea. Si el rol de la familia es desarrollar personas, si se quiere actuar en el ámbito preventivo yendo preferentemente a la raíz de las situaciones de riesgo social, los esfuerzos deben enfocarse al grupo familiar integrando a la familia en el proceso educativo de sus hijos y facilitándole el cumplimiento de su rol. 
Esto no quiere decir que sea responsabilidad exclusiva del Estado o de la sociedad dentro de la cual, con base en la solidaridad, existe la obligación de atender a los miembros o grupos de ésta que están pasando apuros, que tienen problemas de sobrevivencia, que no alcanzan a satisfacer sus necesidades vitales. Pero tampoco es responsabilidad exclusiva de los padres a quienes se les ha negado la posibilidad de acceder a un empleo, educación, etc. (Zanzi, 1993: 207-222, Podal, 1993: 87).

Toda política pública orientada a la familia implica una concepción ideológica del tipo de familia al que se aspira y los principios en que se basa, una fundamentación legal de las normas que socialmente rijan las relaciones familiares y las de la familia con la sociedad, conocimiento científico de la realidad familiar que fundamente una serie de programas correctamente coordinados orientados a la preservación familiar, tales como empleo, recursos económicos, urbanización y vivienda, salud, educación (Leñero, 1976: 108-119, 131-132).

Una política específica para las familias, que se refiere al papel que desempeña el Estado en la vida familiar de los individuos y a los programas relativos al matrimonio, el divorcio, la procreación, la educación y el bienestar de los hijos, el cuidado de los enfermos, los ancianos, los discapacitados, en fin, a todos los problemas vinculados directa o indirectamente con el bienestar familiar, implicaría la búsqueda y realización de objetivos y valores comunes con el propósito de resolver los problemas sociales de las familias.

Esta política específica para la familia sería un conjunto de acciones tendientes a reforzar la institución familiar mediante el mejoramiento de las condiciones de vida en todos los órdenes (económico, jurídico, cultural y otras) de todos los integrantes de las familias, de manera que se favorezca no sólo la satisfacción de sus necesidades, sino también la igualdad entre los ciudadanos y su desarrollo integral y equitativo.

Sin embargo, es habitual que los planificadores del bienestar social conciban políticas y programas destinados a las personas: mujeres, jóvenes, ancianos, enfermos, discapacitados, niños de y en la calle, etc. De esta manera, estas políticas y programas, a veces desarticulados 
unos de otros como si cada uno de ellos atendiera una realidad distinta y diferenciada, no consideran la realidad familiar. Lejos de abordar la problemática familiar desde una perspectiva global, se enfocan a aspectos muy particulares de la fenomenología familiar, sin tomar en cuenta los compromisos que vinculan a los individuos en el marco de sus relaciones familiares.

¿Cómo se pueden satisfacer los intereses de las mujeres, por ejemplo, sin considerar que son esposas, madres, hijas, hermanas, trabajadoras y jefas de familia, si la igualdad ante la ley de hombres y mujeres no se ve en la realidad? ¿Si las políticas de empleo son concebidas como parte de las políticas macroeconómicas y pocas veces se las relaciona con la familia? ¿Si las políticas de desarrollo agropecuario, comunitario, de acceso al crédito y otras no consideran la perspectiva de género? ¿Si no se considera la distancia salarial entre los sexos bajo el prejuicio de que el ingreso de las mujeres es menos importante porque constituye un "ingreso complementario" o de apoyo al marido? ¿Si no se toma en cuenta la reticencia de muchos empleadores a contratar mujeres a causa de la maternidad? ¿Si no existe un sistema eficiente de guarderías que apoye a las mujeres para enfrentar sus necesidades de trabajo? (Ribeiro, 2000: 16-21, 28-29, 31-34, 91-92, 118-119, 233-234). Difícilmente se puede concebir un movimiento de superación en la familia sin un cambio en su estructura que signifique el desarrollo de la capacidad humana, económica y social de la mujer, y un replanteo de su posición frente al hombre como ser humano de igual calidad que él, lo cual implica un cambio de las tareas masculinas dentro y fuera de la familia (Leñero, 1976: 119-131).

Lo anterior muestra un panorama de atomización familiar que hace difícil el involucramiento real y conjunto de las familias para la satisfacción de sus necesidades. Si no se aborda la familia de manera íntegra no se está solucionando verdaderamente el problema en su raíz. Se tiene que compartir la responsabilidad de crianza de los niños apoyando a la familia para el ejercicio del rol de educación de los hijos. No sólo en los aspectos económicos relativos a las necesidades básicas propias de la pobreza, sino también abordar las carencias que se dan en el plano de las necesidades afectivas (Zanzi, 1993: 207222). 
Aunque las personas a quienes estas políticas y programas están dirigidos forman parte de una familia, ésta no es una simple yuxtaposición de individuos. Las familias constituyen unidades caracterizadas por una dinámica propia y constituyen recursos primarios para satisfacer sus necesidades. No son entidades pasivas que se constituyen en receptoras de la acción de agencias externas encargadas de los programas de bienestar social. Se ven afectadas directamente por los problemas de cualquiera de sus miembros y deben implicarse en la búsqueda de soluciones.

Lo anterior implica considerar a las familias no como objetos, sino como sujetos activos de las políticas que las afectan, promoviendo la generación de auto-iniciativas para la solución de sus problemas. Por ello las políticas públicas dirigidas a la familia deben sustentarse en la consulta y la concertación. Partir de la base, pues sólo así se pueden rescatar las legítimas demandas de la población. Deben reconocer la diversidad de estructuras familiares y considerar el entorno siempre abierto en que se desenvuelven las familias, lo cual implica romper los esquemas verticales de intervención gubernamental.

La familia se ha transformado radicalmente a lo largo del último siglo, pero las políticas sociales no han estado a la altura de esos cambios. A veces tienen una perspectiva limitada de lo que es la familia. Lejos de concebirla como una institución plural, dinámica y cambiante, estiman que es una unidad estable, única y casi inmutable. Estas políticas, sustentadas en una visión que reduce la "normalidad" familiar a un modelo único, establecen, fundadas en ese sólo modelo, una normatividad y legalidad que excluyen otras estructuras. La imagen más difundida es la que corresponde al modelo pequeño burgués de familia conyugal nuclear, pero ésta no es la única agrupación familiar y en ocasiones ni siquiera la más representativa.

Aunque la unicidad del modelo simplifica la elaboración de las políticas que atienden a las familias, esto precisamente restringe la concepción de las políticas y limita el alcance de los programas de intervención en materia familiar para resolver la problemática derivada de la multiplicidad de formas de organización familiar, pues se dejan de lado las "otras familias", lo cual provoca frecuentemente que éstas sean percibidas como casos "desviados", provocando con ello la 
marginalización de estructuras familiares diferentes (Ribeiro, 2000: $36-37,65-66,122,221)$.

A lo anterior también contribuyen, además de la iglesia, las respuestas asistencialistas institucionales y la práctica profesional pragmática y rutinaria de algunos promotores sociales que desempeñan el rol que la sociedad capitalista les ha asignado, y que los convierte en expertos que saben lo que los individuos y las familias deben hacer, desechando sus valores adquiridos en la vida cotidiana, y que los lleva a etiquetar sujetos y familias (familias disfuncionales, menores con trastornos de conducta, etc.).

Aunque en el discurso se repite a menudo que los patrones culturales deben ser respetados, generalmente se trata a los sujetos y a las familias de acuerdo con el modelo de familia burguesa, (el padre que provee, la madre que cuida de la casa y los hijos, etc.) y más aún, considerados de manera aislada sin tomar en cuenta que los problemas individuales y familiares son expresión de lo social y que cada problema, individuo, familia, situación, son diferentes. De esta manera, su práctica subordinada a las demandas institucionales, al mismo tiempo que resulta funcional para la dinámica institucional, contribuye a reforzar la violencia institucional a que son sometidos los individuos y las familias por quienes, en nombre de los que detentan el poder los asisten, legitimando con ello el orden social.

Así, las políticas asistenciales para la familia han sido ejecutadas por los profesionales y han funcionado como estrategias reguladoras de las condiciones de reproducción social (Barg, 2000: 70, 88, 83-90, $118,125)$. No hay que olvidar que las políticas de bienestar social no sólo se han diseñado para lograr metas de mayor equidad social; también juegan un papel importante en la legitimación de los sistemas políticos, en la reproducción social y en el mantenimiento del orden público; sin olvidar también su uso con fines electorales (Ribeiro, 2000: 34).

A menudo las políticas asistenciales para la familia se han apoyado no sólo en matrices de favor y clientelismo, sino también en prácticas discriminatorias que reproducen relaciones de poder y subordinación; coercitivas, intimidatorias y hasta punitivas, que refuerzan la figura del padre y del necesitado, sometiendo al grupo familiar a rituales 
comprobatorios de su situación de miseria en nombre de la meritocracia para la asignación de recursos que se ha usado como mecanismo de estabilización de las relaciones sociales. Como por ejemplo, con proyectos impregnados de cultura tutelar, de responsabilidad individual y de autogestión, para justificar el desplazamiento del Estado de sus responsabilidades sociales que se lanzan perversamente al mercado.

No existe un modelo familiar de padre, de madre, de hija, de hijo, sino familias, padres, madres, hijos, hijas, que se relacionan de maneras diversas que están ligadas a la historia personal de vida y de ver el mundo que a menudo no es igual a la nuestra. Si no aceptamos la diversidad de los sujetos y familias conceptualizándolos como sujetos históricos capaces de colaborar en la transformación de las relaciones sociales, difícilmente podremos pensar en una metodología diferente para abordarlos sin recetas (Barg, 200: 98, 130-131).

Cualquier política o programa de la familia debe partir del reconocimiento de la pluralidad familiar y de la diversidad de normas, valores y pautas de comportamiento para dar respuestas específicas a necesidades diferenciadas respetando la identidad y autonomía de las unidades familiares. Por tal razón no se pueden concebir las políticas sociales por separado. El Estado debe tomar en cuenta a la familia en el conjunto de sus políticas sociales. La política familiar debe ser multisectorial. Desarrollarse a partir de la integración de la dimensión familiar de la vida de las personas en todos los sectores sociales, porque la familia constituye un medio de vida profundamente relacionado con los otros contextos de la vida social (económico, político, cultural, etc.). Por ello la política familiar debe integrarse con las políticas de planeación y desarrollo regional, agrario, de industrialización y de urbanización; con las políticas de empleo, educación, vivienda, salud y otras. Debe vincularse con las otras políticas sociales con el propósito de articular los esfuerzos del Estado y de la sociedad en la construcción del bienestar familiar y social.

En esto, ni el Estado ni la sociedad pueden actuar solos o de manera independiente. Es necesario unir esfuerzos para crear las condiciones propicias para que las familias puedan potenciar y articular sus recursos 
materiales, humanos y culturales, para enfrentar la satisfacción de sus necesidades o la solución de sus problemas (Ribeiro, 2000: 36-39, 41, $68,222-225)$.

El Estado en su rol de gestor de políticas públicas, con el apoyo de la sociedad en donde se incluye el grupo familiar (no solamente individuos), debe mejorar la cobertura y calidad de los programas sociales. Subsanar las deficiencias u omisiones que han venido a ser cubiertas por organismos no gubernamentales a través de programas alternativos con recursos propios. Esto debe traducirse en la articulación de un esfuerzo integrado de toda la sociedad en defensa y protección de la familia y la comunidad, que redunde en proporcionar a los sectores pobres el nivel de capital humano que los saque definitivamente de su situación (Zanzi, 1993: 207-222). El mejoramiento de la familia no puede ser ajeno al desarrollo social. Por ello, el interés en la familia no es sólo un interés privado, sino que adquiere necesariamente una dimensión colectiva y pública (Leñero, 1976: 119-131. Segalen, 1992: 13-28).

\section{Conclusiones}

El Estado de bienestar, entendido como la protección gubernamental mínima en los niveles básicos de ingreso, vivienda, nutrición, salud, educación, etc. asegurados a cada ciudadano como un derecho, y que se consolidó a partir de la primera mitad del siglo XX, logró una conjugación importante entre capital y trabajo mediante la intervención estatal centralizada coordinada con la clase obrera organizada, cuyo papel fue central en la definición de prioridades que definieron a su vez la agenda pública del Estado, gracias al desarrollo de políticas sociales que estructuraron el sistema de protección de la clase trabajadora y de los ciudadanos en general.

Mediante una relación de tipo corporativo con la clase trabajadora organizada en la que ésta lograba beneficios y el Estado legitimidad, buscó el empleo pleno, logró un crecimiento económico y un proceso de inclusión de las políticas económicas y sociales, lo que significó una forma de movilidad social ascendente. En este Estado la noción de desarrollo estaba ligada a las nociones de igualdad y justicia social en concordancia con las ideas de progreso. Si bien siempre tuvo como contrapartida la persistencia de las desigualdades sociales generadas 
por la distribución desigual de la riqueza, generó cierta paz social. Aunque no fue una solución definitiva ni ideal, por lo menos buscó reducir las desigualdades sociales y logró vincular crecimiento económico con bienestar social (Rozas, 2001: 157-158).

Cuando el Estado entró en crisis fue sustituido por uno capitalista neoliberal. Se da una redefinición de poder entre capital y trabajo, se perdió la centralidad de la clase trabajadora para articular el derecho al trabajo con la protección social gestionada por el Estado (Rozas, 2001: 175, 197-199). La flexibilidad laboral implantada con el nuevo Estado se traduce en facilidades para despedir trabajadores y reducir prestaciones. Con esto el mundo del trabajo se fragmenta y los trabajadores se convierten en individuos atomizados, abandonados a su propia suerte, responsables de su propia vida, porque se les ha colocado al margen de las regulaciones o protecciones que permitían la reproducción de una sociedad asalariada (Vite, 2003: 31-36, 40, 5254).

El Estado ha sido reducido y vaciado de sus responsabilidades y funciones, así como de sus capacidades reguladoras y de decisión legislativa, y alineado y puesto al servicio de los intereses de la clase capitalista multinacional. Dejó de ser una fuerza mediadora entre la globalización y el bienestar de la población para transformarse en un instrumento de respaldo a los flujos internacionales de capital y tráfico de mercancías (Petras, 2002: 27, 32, 56). Se postula que el Estado no debe intervenir en la asignación de recursos ni en la inversión productiva y su intervención se limita a ciertos sectores no mercantiles: la salud, (sobre todo políticas preventivas), la educación (sobre todo la educación básica), y la infraestructura: transporte, energía, etc. (Salama, 1999: 165).

Se desmontó la institucionalidad a través de la cual las demandas de la población y las respuestas del Estado interactuaban. En lugar de la red de seguridad social se implantó una concepción según la cual el bienestar es un asunto privado, responsabilidad de los individuos cuyas necesidades deben ser resueltas en el ámbito de la familia en el mercado de los servicios privados. Lo anterior ha significado un retroceso que 
ha afectado principalmente a las capas medias y a los grupos más pobres de la sociedad (Filgueira, 1999: 163, 205).

Esto ha afectado seriamente a las familias. Éstas reciben todas las influencias de la sociedad y no pueden operar fuera de sus directas conexiones con ella. Reciben el impacto de este proceso tanto en sus aspectos positivos como negativos. No puede variar la organización familiar sin que las consecuencias de ese cambio se extiendan al resto de la organización social (Leñero, 1991: 25). La mayor frecuencia de la violencia intradoméstica y social en general, pudieran ser expresiones indirectas de la crisis socioeconómica que se refleja en las familias (COMEXANI. 1994: 205-206. Ribeiro, 2000: 60-61, 113).

La familia debía producir la felicidad de los individuos a su cargo. Sin embargo, a partir de los años setenta deja de ser capaz de satisfacer estos deseos; se rompe, toma formas inéditas. Al menos esto indica las diversas formas de cohabitación fuera del matrimonio, los altos índices de divorcio, las familias monoparentales, reconstituidas, etc. Si está en situación crítica de desintegración interna como consecuencia de la crisis económica, difícilmente puede operar sanamente (Segalen, 1992: 13-28). Desde este punto de vista, la familia puede servir como impulsora o como freno del proceso de modernización entendido como la totalidad de las acciones que orientan a la sociedad hacia la consecución de un conjunto ordenado de condiciones de vidas individuales y colectivas que se estiman deseables con respecto a determinados valores (Mena, 1993: 5-14).

El desarrollo social debe empezar por el mejoramiento de la familia y para esto el empleo es un aspecto crucial. Ninguna red de seguridad social puede reemplazar completamente la seguridad provista por una economía de empleo pleno (Stiglitz, 2001: 2-6, 8-12, 14-15). Las políticas públicas de mayor éxito contra la pobreza no son los programas asistenciales, sino los programas que inciden sobre el mercado laboral aumentando el empleo y el nivel de los salarios (Pando, 2003: 3-4).

El problema no es "incorporar" a los millones de ciudadanos pobres al orden social vigente que los mantiene en la miseria. Lo que se requiere es cambiar ese orden social para que dejen de ser marginados (Sandoval, 
1999: 193). El problema está pues en parte, en la incapacidad de los gobernantes para vislumbrar otras opciones económicas o en su dolosa negativa para aceptar el cambio para no afectar sus propios intereses económicos. A pesar de que la realidad cotidiana muestra el fracaso de las políticas económicas implementadas, continúan promoviéndolas independientemente de que sus efectos negativos sobrepasan a los positivos, acumulando costos sociales cada vez más intolerables.

En esta situación, culpar al capitalismo de todos los problemas puede resultar reconfortante psicológicamente, pero las causas fundamentales de muchos de los problemas son internas y se tienen que resolver internamente. El medio externo se ha sabido aprovechar de la situación y en ese proceso ha contribuido a mantenerla, pero el superarla está en nuestras manos.

En este marco, el problema de fondo sigue siendo una economía que ha pesar del alto costo de su transformación aún sigue sin encontrar la manera de reactivar al conjunto del aparato productivo para dar el empleo que la demografía demanda, con una remuneración a la altura de la preservación de la dignidad humana, y que pone en riesgo la preservación de las instituciones democráticas que están naciendo. Así, los temas centrales de la política de hoy están en el campo económico y en el de los programas sociales en materia de políticas de empleo, de redistribución del ingreso y de justicia social (Magee, 1994: 114-117. Meyer, 1998: 128-129).

México, por ejemplo, es un país de jóvenes a los que no se les ofrece un entorno favorable desde la familia; 32 millones de mexicanos son menores de 14 años; 18 millones son jóvenes de uno y otro sexo entre 15 y 24 años de edad; son el $22 \%$ de la población total del país y constituyen el $30 \%$ de la población económicamente activa (CONAPO, 1995: 18, 65) ¿Cómo vamos a incorporar al mercado a los millones de jóvenes que se suman cada año a la fuerza laboral si el déficit de empleos se incrementa cada vez más y los puestos de trabajo que se generan ni siquiera alcanzan a reponer los que se pierden? ¿Qué hacen los jóvenes que no tienen acceso a la escuela y no pueden conseguir un empleo? Probablemente esto está detrás del incremento de los delitos cometidos por jóvenes. 
Es desde la familia que debe afrontarse la situación de colapso del ingreso y de la fragilidad social a que se ha llevado no sólo a la familia, sino a la sociedad en general (Podal, 1993: 96). Es importante iniciar por el empleo; el trabajo es una necesidad vital del hombre que debe trabajar para sobrevivir, por lo que el derecho a trabajar nace del derecho a vivir. Este derecho al trabajo resulta fundamental en el orden social porque el hombre que no trabaja no contribuye con su esfuerzo útil al desarrollo del país. De aquí que, correlativo al derecho al trabajo, es la obligación del Estado de combatir el desempleo. No se trata sólo de entender este derecho como garantía constitucional, sino como atributo de la persona, ya que el hombre que no trabaja carece de los medios necesarios para desenvolverse. Tampoco se trata sólo de otorgar ocupación; ésta involucra condiciones dignas de trabajo y un salario que satisfaga con decoro los requerimientos mínimos de la existencia cotidiana del trabajador y su familia (Lastra, 1993: 17-19).

\section{REFERENCIAS}

Barg, Liliana. (2000). La intervención con familia. Una perspectiva desde el trabajo social, Buenos Aires, Espacio Editorial, pp. 70, 83-93, 98, 118, 125, 130-131.

COMEXANI. (1994). Los Niños del Otro México. México, Tercer Informe Sobre los Derechos del Niño y la Situación de la Infancia en México, pp. 205-206.

CONAPO. (1995). Situación de la mujer. Desafíos para el año 2000, México, Consejo Nacional de Población, $2^{\mathrm{a}}$. Reimpresión, pp. 18, 29,65 .

Cortázar, René. (1999). Globalización y creación de puestos de trabajo. Una perspectiva latinoamericana, en Tockman, Víctor y Guillermo O’Donnell (comp.). Pobreza y desigualdad en América Latina, Buenos Aires, Paidós, p. 99. 
Filgueira, Carlos. (1999). Bienestar y ciudadanía. Viejas y nuevas vulnerabilidades, en Tockman, Víctor y Guillermo O'Donnell (comp.) Pobreza y desigualdad en América Latina Buenos Aires, Paidós, pp. 163, 205.

Hernández, Guillermo. (1999). Obreros, el colapso salarial, Guadalajara, Jalisco, México, Periódico Mural del 1 de mayo, p. 10A.

Laurell, Asa Cristina. (1998). Reseña de su libro La Reforma contra la salud y la Seguridad Social, Era-Fundación Friedrich Ebert, (122 páginas), México, 1997, en Revista Trabajo, segunda época, año 1, número 2, julio-diciembre, México, pp. 179-182.

Lastra Lastra, José Manuel. (1993). Derechos humanos, Revista Jurídica Jalisciense, año 3, número 6, mayo-agosto, Instituto de Investigaciones Jurídicas, Guadalajara, Jalisco, México, Universidad de Guadalajara, pp. 17-19.

Leñero Otero, Luis. (1976). La familia, Colima, Col. México, ANUIES, pp. 108-132.

Leñero Otero, Luis. (1991). El niño sin familia y sin sociedad propia, Colima, col. México, Memoria del Primer Foro Nacional del Menor en la calle, celebrado del 13 al 15 de junio p. 25.

Magee, Bryan. (1994). Popper, España, Colofón, pp. 114-117

Mena, Carlos, Mariana Aylwin y Cristian Gazmori. (1993). La familia en Chile, Santiago de Chile, Instituto Chileno de Estudios Humanísticos, 2a . ed. pp. 5-14.

Meyer, Lorenzo. (1998). Fin de régimen y democracia incipiente, México, Océano, pp. 128-129.

O’Donnell, Guillermo. (1999). Pobreza y desigualdad en América Latina. Algunas reflexiones politicas, en Tockman, Víctor y Guillermo O'Donnell (comp.) Pobreza y desigualdad en América Latina, Buenos Aires, Paidós, pp. 78, 160-161. 
Pando, Diego. (2003). La problemática social contemporánea en América Latina, Revista electrónica DHIAL, número 42, 10 de junio, en el Boletín número 154 Barcelona, Instituto Internacional de Gobernabilidad, iig@iigov.org pp. 1, 3-4, 6-8, 11.

Petras, James y Henry Veltmeyer. (2002). El imperialismo en el siglo $X X I$, Madrid, Editorial Popular, pp. 24, 27-28, 32, 56.

Podal Farrús, Monserrat. (1993). Pautas educativas en la familia, en Quintana, José María, Pedagogía Familiar, Madrid, Narcea, p. $87,96$.

Ribeiro Ferreira, Manuel. (2000). Familia y Política social, Buenos Aires, Humanitas, pp. 16-21, 28-29, 31-34, 36-41, 77-78, 91-92, $113,118-119,122,124,221-225$.

Rozas Pagaza, Margarita. (2001). La intervención profesional en relación con la cuestión social, Buenos Aires, Espacio Editorial, pp. 86, 99-101, 153-158, 173-179, 181, 197-199, 214, 216-217.

Salama, Pierre. (1999). Riqueza y pobreza en América Latina. La fragilidad de las nuevas políticas económicas, México, FCE, pp. $165,255-256,259-264$.

Segalen, Martine. (1992). Antropología histórica de la familia, Madrid, Taurus, pp. 13-28,

Stiglitz, Joseph. (2001). Participación y desarrollo: perspectivas desde el paradigma integral de desarrollo, Revista Instituciones y Desarrollo número 7, noviembre, Barcelona, Instituto Internacional de Gobernabilidad, pp. 2-6, 8-12, 14-15. http://www.iigov.org/ iigov/pund/bibliote/revista/revista7/docs/participación.htm

Tamez González, Silvia. (1998). La Reforma de la Seguridad Social en América Latina, Culminación de la Política Social Neoliberal, México, Revista Trabajo, segunda época, año 1, número 2, juliodiciembre, pp. 6-9.

Torre, Juan Carlos. (1998). El proceso político de las reformas económicas en América Latina, Buenos Aires, Paidós, pp. 114. 
Vite Pérez, Miguel Angel. (2003). Globalización y modernidad: más allá de las definiciones, Espiral, volumen 9, número 27, mayo/ agosto, Guadalajara, Jalisco, México, Universidad de Guadalajara, pp. 31-36, 40, 49-54.

Zanzi Garcilic, Oriana. (1993). La familia en la resolución de problemas de niños y jóvenes en situación de riesgo, en $\underline{\mathrm{La}}$ familia en Chile, Santiago de Chile, Instituto Chileno de Estudios Humanísticos, $2^{\mathrm{a}}$. ed. pp. 207-222. 